\title{
IMPLEMENTING THE UNFEASIBLE: testing for alleged sexual offenders
}

\author{
Stefanie Roehrs \\ Gender, Health \& Justice Research Unit, UCT \\ steffie.rohrs@uct.ac.za
}

Since being approved by both the National Assembly and the National Council of Provinces, it seems likely that the provisions on compulsory HIV testing of alleged sexual offenders will soon be enacted as part of the new Criminal Law (Sexual O ffences and Related Matters) Amendment Bill. Whereas an earlier article (see SA Crime Q uarterly 20, 2007), questioned the constitutionality of the provisions, this commentary focuses on the implementation challenges of compulsory HIV testing. Despite good intentions, these provisions will not actually be useful for rape complainants. Instead, the potential exists that rape complainants will be endangered and criminalised. Another concern is the feasibility of compulsory HIV testing, which will place an overwhelming burden on the police, who have neither the resources nor the training to provide such services.

T he new Criminal Law (Sexual O ffences and Related Matters) Amendment Bill (2006) (hereafter: the Bill) aims to address two ills of contemporary South Africa: the large number of sexual offences and the high prevalence of HIV/Aids. The draft legislation is ambitious: 'to combat and ultimately eradicate the relatively high incidence of sexual offences committed in the Republic' (Sexual Offences Bill Section 2). To achieve this aim, it is essential to protect 'complainants of sexual offences and their families from secondary victimisation and trauma' through a 'responsive and sensitive criminal justice system' (Section 2 (d)).

In many instances the Bill effectively pursues this aim, for instance where new sexual offences are created or the definitions of out-dated common law crimes are amended. The provisions on compulsory HIV testing of alleged sexual offenders, how ever, remain a major weakness of the proposed legislation.

\section{Compulsory HIV testing provisions}

The legislation allows both male and female victims of sexual offences to apply for a compulsory HIV test of the accused sexual offender. The application has two requirements:

- The victim must lay a criminal charge with the South African Police Service (SAPS)

- Not more than 90 days must have passed since the alleged commission of the crime

If these requirements are fulfilled, the victim may apply for a mandatory HIV test of the accused at the police station. The police have to submit the application to a magistrate who must make an order for the alleged sexual offender to be tested for HIV, if satisfied that: a sexual offence has been committed against the victim by the alleged 
offender; the victim may have been exposed to the body fluids of the alleged offender; and no more than 90 calendar days have lapsed since the commission of the alleged offence.

The magistrate will then inform the police of the outcome of the application. The police, in turn, must inform the applicant and, where appropriate, make the accused available for the HIV test. The test has to be performed at a designated health facility. The test result will be forwarded to the police who must inform the applicant and the alleged offender of the outcome of the HIV test.

\section{Compulsory HIV testing - a victims' service?}

Compulsory HIV testing of the alleged sexual offender is thought to be one of the new, progressive services for rape complainants. However, compulsory HIV testing fails to assist rape victims and may even lead to adverse consequences for those who make use of it. The main concerns are threefold. The provisions on compulsory HIV testing:

- Create a false sense of security in rape victims

- Criminalise rape victims

- Put rape victims at risk for retaliation

False sense of security

Giving victims the opportunity to apply for an HIV test of the alleged sexual offender implies that the test result is somehow relevant to them. The Bill suggests that testing the accused will help:

reducing secondary trauma and empowering the victim to make informed medical, lifestyle and other personal decisions (Sexual O ffences Bill Section 34 (a) (i)).

Unfortunately, compulsory HIV testing neither helps victims to make 'medical decisions' around postexposure prophylaxis (PEP) 1 nor 'lifestyle decisions' around safer sex, because the test result is unreliable. It may, but does not necessarily, reflect the accused's HIV status because the alleged offender may be in the 'window period' when s/he is tested for HIV. This means the HIV test result might be negative although the accused is HIV positive.

Consequently, victims who base their medical or lifestyle decisions on the test result may, in fact, run an increased risk of getting infected with the virus. If, for instance, a victim stops taking PEP, or stops practising safer sex, because the test of the alleged offender came back negative, $s /$ he is at an increased risk for contracting HIV. The emotional impact of testing and waiting for results should also not be underestimated.

The legislation is therefore very misleading and without in-depth education of the victim - will jeopardise the physical and psychological well-being of victims and their consensual sexual partners.

\section{Criminalisation of victims}

The legislation can lead to the criminalisation of victims on two counts: criminalising 'malicious applications' and criminalising HIV disclosure.

\section{Criminalising 'malicious applications'}

Research indicates that only 7 per cent of reported rape cases ever result in a conviction of the accused (Amnesty International 2005). Accordingly, the vast majority of alleged offenders walk free after the criminal proceedings. Under these circumstances, those acquitted who were forced to undergo compulsory HIV testing may try to retaliate against the victim, for instance by filing a civil suit. It is possible that civil courts will grant damage claims for those who had to undergo HIV testing but were later acquitted.

As if the risk of civil liability was not enough, the proposed legislation also provides for criminal charges against rape complainants. O ne may even argue that the Bill encourages alleged perpetrators to initiate a prosecution of the victim by stating that:

Any person who, with malicious intent lays a charge with the South African Police Service in respect of an alleged sexual offence and makes an application [...], with the intention of ascertaining the HIV status of any person, is guilty of an offence and is liable on conviction to a fine or to imprisonment for a period not exceeding three years (Sexual O ffences Bill 38 (1)(a)).

Victims may therefore be prosecuted for laying a charge and requesting an HIV test with malicious intent. Even though the provision only criminalises 'malicious' behaviour, it raises serious concerns. 
First, it appears contradictory that legislators allow victims to apply for an HIV test of the accused, knowing that the conviction rates are extremely low, and at the same time allow the prosecution of the victim for malicious intent. Second, such a provision may well deter victims from laying a charge in the first place. Besides, taking into account the emotional state of the rape victim and the amount of information required, it may, in fact, be unrealistic to expect a rape victim to fully comprehend such legal technicalities.

Deterring victims from reporting sexual offences is particularly problematic because rape is already highly underreported. Whereas the SAPS estimates that one in three rapes is reported (SAPS Annual Report 2003), Jewkes \& Abrahams (2002) found that only 15 per cent of rape victims between 15 and 49 years report it to the police. Underreporting makes it difficult for the police to effectively address sexual offences. Hence, driving these offences further underground cannot be in the interests of justice.

Legislation promoting the prosecution of rape victims clearly sends out the wrong message. Whereas the blame should be on the perpetrator, the relevant provision may shift the blame onto the complainant by criminalising her or his conduct.

\section{Criminalising HIV disclosure}

Another concern is section 38 (b) of the Bill:

Any person who with malicious intent or who in a grossly negligent manner discloses the results of any HIV tests [... ] is guilty of an offence and is liable to a fine or to imprisonment for a period not exceeding three years.

This provision applies to anyone who discloses the test result to a person other than:

- The victim or the interested person

- The alleged offender

- The investigating officer

- Where applicable, to a prosecutor or any other person who needs to know the test results for purposes of any civil proceedings or a court order

Accordingly, the victim must not let anybody know of the outcome of the test result, or otherwise faces penalties. Although the protection of the alleged offender's privacy is understandable, it is unreasonable that the Bill broadly criminalises disclosures by rape victims.

Testing a person for HIV against their will and then disclosing the test result to another individual constitutes a tremendous violation of privacy. But if in the opinion of the legislators - the victim's 'right to know' outweighs the privacy of the accused and thus justifies the creation of compulsory HIV testing provisions, the legislation should follow through with this. The victim should at least be allowed to disclose the test result to his or her (sexual) partner, counsellor, GP or immediate family members. Since the victim finds him- or herself in a state of shock and trauma after the sexual offence, it is vital for her or his psychological wellbeing to speak to others about the sexual offence, its consequences and entailed risks. Also, if the victim cannot read the written result, s/he may have to ask a friend or relative to read it.

The only safeguard that may protect the victim from being prosecuted is that the prosecution needs to be authorised in writing by the Director of Public Prosecutions. Hopefully, this will prevent negative publicity about victims. It would indeed be better if the provision did not apply to victims or, at least, only penalised malicious disclosures.

\section{Endangering rape victims}

Another important issue that the Bill fails to consider is the personal safety and security of the victim during the application process. If the alleged offender has not been arrested or is out on bail, the victim's safety is severely at risk once the alleged offender is asked to do the HIV test. The accused is likely to feel deeply resentful at having to undergo a compulsory HIV test. There is a real possibility that the accused whether s/he committed the crime or not - will try to intimidate the victim in order to get her or him to withdraw the application. It must also be remembered that HIV and Aids are still highly stigmatised in our communities. An alleged offender will therefore be extremely reluctant to be tested.

The Bill fails to provide for any measures to protect the victim from threats by the alleged offender. It seems unrealistic that the police, who are already over-burdened with the whole process, will be able to 
provide additional support for the victim, unless it is a statutory obligation.

\section{0 verburdening an under-resourced police service} Besides the serious implications for rape victims it remains questionable whether the provisions will be feasible. Compulsory HIV testing is a complex process. Its implementation requires an efficient and swift response from various role players in the health and criminal justice system, but mostly from the police. The SAPS, already understaffed and underresourced, will struggle to implement the manifold duties that the Bill imposes on them.

The members of the police bear the greatest brunt at the implementation stage because they have to:

- Inform the victim of services available, including the option of applying for a compulsory HIV testing order

- Run between the police station and the magistrate's court to submit applications and collect orders

- Inform the applicant and the accused of the outcome of the application

- Make the alleged offender available for the HIV test, which may include making an application for a warrant of arrest if the accused fails to comply with the order

- Request a medical practitioner or nurse to take two blood samples of the alleged offender

- Deliver the blood samples to the head of the (designated) health establishment and request that an HIV test be performed

- Hand sealed envelopes with the test result to the applicant and the accused

Before examining some of those duties individually, the entire list raises a number of concerns.

\section{General concerns}

The various duties listed above will significantly increase the workload of police officers dealing with sexual offences. It is unclear how an understaffed and under-resourced police service that is already struggling to fight crime and deliver 'regular' services, can be expected to comply with these additional duties, especially since most of these services must be delivered 'as soon as is reasonably practicable'. ${ }^{2}$ According to Leggett (2003), 'If combating crime [...] is seen as the primary purpose of the police, there is clearly a need for a reallocation of resources'.

Not only does the Bill create a number of new duties, but some of these duties appear particularly timeconsuming, for instance: submitting the application to the magistrates court; collecting the court order; bringing the accused to a health facility for a blood sample and delivering the blood sample to the head of the health facility for an HIV test.

The increased workload requires that the budget of the SAPS be adjusted accordingly, and human resources be increased. Possibly, police 'infrastructure' (extra cars, for instance) will have to be upgraded, requiring finance. Furthermore, the implementation of the legislation will require comprehensive in-depth training of all police officials dealing with sexual offences. Training should not only focus on the provisions on compulsory HIV testing, but should also include education on 'soft skills'.

Police officers are often not trained in 'soft skills' because they see their task as 'bringing criminals to book'. Research monitoring the implementation of the Domestic Violence Act (1998) shows that victims of domestic violence who turn to the police are often treated with a lack of respect and sympathy (Parenzee et al 2001:83). Asking the police to deal with sensitive issues such as forced HIV tests overestimates current police qualifications and underestimates the impact of involuntary HIV tests. W hether police officials should, in fact, be assigned to deal with such delicate health matters is a different question altogether.

Individual duties

These raise a number of concerns:

\section{Information}

According to the Bill, the police official must inform the victim of:

- The importance of obtaining PEP for HIV infection within 72 hours after the alleged sexual offence took place

- The need to obtain medical advice and assistance regarding the possibility of other sexually transmitted infections

- The following services and details:

- Provision of free medical advice surrounding the administering of PEP 
- Provision of PEP for HIV infection at a public health establishment at state expense

- A list with names and contact particulars of accessible public health establishments

- The option of applying to a magistrate for an order that the alleged offender be tested for HIV at state expense

The provision of this vital information will greatly benefit the victim. O nly when victims know their rights, can they exercise them. However, this kind of information must be explained to the victim comprehensively and understandably. This, in turn, requires that police officials are trained comprehensively on sexual offences, HIV transmission, PEP and compulsory HIV testing to ensure the information they provide is correct and any questions by the rape survivor (e.g. 'W hat is PEP?') can be answered appropriately.

\section{Finding the accused}

An application for a compulsory HIV test can only be made up to 90 days after the alleged commission of the offence. It is questionable how the police are supposed to find the suspect within this time frame, as the investigation of rape cases is notoriously difficult because generally there is only one witness (the complainant), and, besides the victim's body, there is no real 'crime scene' where signs of the perpetrator can be found.

Although research indicates that more than half the rapes in South Africa are committed by a person known to the victim, this does not necessarily facilitate the search for and/or arrest of the offender (Simelela/M edecins Sans Frontieres 2006:17 and Roland et al 2005). A study from Khayelitsha, for instance, found that only a third of all rapists are arrested (Simelela/Medecins Sans Frontieres 2006:17). O ne explanation for this poor arrest rate is that the term 'known to the victim' often means that the victim knew the perpetrator by sight (Roland et al 2005). Thus the name, address or other personal details remain unknown to both the victim and the police. Finding the perpetrator may be even more difficult in multiple perpetrator rapes, which account for approximately 25 per cent of rapes. ${ }^{3}$

Another problem may be that once the accused has been found and notified of the court order, s/he may go into hiding. This highlights another problematic issue of the provisions: the 90-day time frame. Unless the notification and the HIV testing are done at the same time, the accused may hide, wait until the 90 days have passed, and thereby avoid HIV testing altogether.

\section{Test results}

The final task of the police is to inform the applicant and the alleged offender of the outcome of the HIV test by handing them a sealed envelope with the test result as well as a 'notice containing prescribed information on the confidentiality of and how to deal with the HIV test results'. This procedure leaves it up to the victim and the alleged offender to decide whether, when and where they want to expose themselves to the test result. While it may seem reasonable to give the recipients these choices, it is highly alarming that the victim and the alleged offender will not receive any post-test counselling regarding the test result.

Voluntary HIV testing includes pre- and post-test counselling (DoH 2003). Whereas pre-test counselling ensures that the individual has sufficient information to make an informed decision about having an HIV test, post-test counselling is the counselling that is provided by a health worker or HIV counsellor when an individual receives his or her HIV test result. It seems unethical that the alleged offender will not receive any counselling, even though compulsory HIV testing does not require the suspect to consent to the test. How ever, it may be desirable to give the alleged offender at least some basic information around the disease that $\mathrm{s} /$ he is going to be tested for (e.g. what is HIV, how is it transmitted, etc.) before performing the test.

The real issue though, is post-test counselling. Posttest counselling is particularly important for the support of persons who test HIV positive.

According to national health policy (DoH 2003), post-test counselling should include discussions on:

- Feedback and understanding of results

- If the result is negative:

- Strategies for risk reduction

- Possibility of infection in the 'window period'

- If the result is positive: 
- Immediate emotional reaction and concerns

- Personal, family and social implications

- Difficulties a patient may foresee and possible coping strategies

-Who the client wants to share the results with, including responsibilities to sexual partners

- Immediate needs and social support

- Follow up supportive counselling

- Follow up medical care

Post-test counselling is normally provided by the health worker who discloses the test result to the patient. In the case of compulsory HIV testing, though, the police official is the 'messenger' of the test result: s/he hands out the sealed envelope to both the victim and the alleged offender. Hence, there will be no post-test counselling, leaving the alleged perpetrator apprehensive and emotional. At the very least $\mathrm{s} / \mathrm{he}$ should be provided with contact details of organisations that offer support services for people living with HIV/Aids.

With regard to the victim, one may argue that posttest counselling is not necessary because it is not his or her HIV test. However, rape victims could misinterpret the test result of the alleged offender in the belief that the accused's status reflects their own status. It is therefore important to educate the victim about the implications of the 'window period'. And if the test result of the alleged rapist comes back HIV positive, this also requires counselling of the victim. Post-test counselling for victims, explaining the implications of the test result of the accused, is therefore essential.

\section{Conclusion}

Compulsory HIV testing was designed as a tool to assist survivors in the aftermath of rape. Regrettably, it seems that it in fact bears more risks than benefits for victims of sexual violence and that its feasibility remains uncertain, to say the least.

The core problem of compulsory HIV testing is its limited utility for rape victims. The provisions are misleading when they suggest that testing rape suspects for HIV can assist victims to make informed medical and lifestyle decisions.

Besides, the procedures jeopardise the victim's safety and security during the application process and ignore the victim's need for support once the test results are handed to them. The Bill, furthermore, seems to have lost track of its objectives (and of the real problems) when it criminalises rape survivors for malicious applications and unauthorised HIV disclosures.

The successful implementation of the provisions relies on the performance of the SAPS, because the legislation draws heavily on the police. Members of the SAPS will need to provide a number of new services that are not typically associated with investigating crime or with police tasks. It is unclear how the police are expected to cope with these additional tasks without upgrading or reallocating their financial and human resources.

\section{References}

Amnesty International 2005 Annual Report 2005. Available at http://web.amnesty.org/report2005/zaf-summary-eng [accessed 12/10/2007].

Department of Health 2003. D raft National Policy on Testing for HIV. Available at http://www.doh.gov.za/aids/docs/ policy.html [accessed 15/10/2007].

Domestic Violence Act N o. 116 of 1998.

Jewkes R \& Abrahams N 2002. The Epidemiology of Rape and Sexual Coercion in South Africa: An O verview. Social Science and Medicine, 55 (7):1235.

Leggett, T 2003. What do the police do? Performance measurement and the SAPS. Institute for Security Studies, O ccasional Paper No 66.

Parenzee, P, Artz, L, M oult, K (The Consortium on Violence Against Women) 2001. Monitoring the Implementation of the Domestic Violence Act.

Roland, M, Myer, L, Chuunga, R, Martin, L, Maw, A, Coates, T, Denny, L 2005. A Prospective Study of Post-exposure Prophylaxis Following Sexual Assault in Cape Town. Power Point Presentation, Slide 13.

SAPS Annual Report of the National Commissioner of the South African Police Service 2003. Pretoria: SAPS.

Simelela/M edecins Sans Frontieres 2006. Surviving Rape.

\section{Endnotes}

1 Post exposure prophylaxis is a 28-day programme of antiretroviral drugs, which may prevent the infection of HIV if taken within 72 hours of exposure to HIV. Scientific evidence suggests that the medication needs to be taken within 6 hours of exposure to be effective.

2 See sections 30 (4), 31 (5), 33 (1) of the Bill.

3 See Roland et al, Slide 12. The Bill does not make any specific provision for these cases but only refers to testing 'the alleged offender' (s 30 (1) (a) (i) of the Bill). 